\title{
THE VALUE OF INFORMATION IN SALMON FARMING. HARVESTING THE RIGHT FISH AT THE RIGHT TIME
}

\author{
Odd Inge Forsberg $\square$ Integral Aquaculture Ltd., Norway \\ Atle G. Guttormsen $\square$ Department of Economics and Resource Management, \\ Norwegian University of Life Sciences, Aas, Norway
}

Research on management practices in fish farming has traditionally focused on two topics: production planning and forecasting of prices. This article combines these two areas of research, and illustrates how information on price patterns can change production plans, and hence increase the value of the farm enterprise. It will present a model farm and illustrate, with different levels of price information, how information on future prices alters the original production plan and hence creates extra value for the farmer. Although the specifics and empirical application of the paper are on salmon and salmon farming, the ideas and general results could be applied to all farmed species.

Keywords optimal harvesting, salmon prices, value of information

\section{INTRODUCTION}

During the last two decades, the salmon farming industry in Norway has moved from a local small-scale industry to a global, multinational, billion dollar industry. However, despite its impressive growth the industry has experienced a high degree of turbulence and large cross-sectional variations in profitability. This has manifested itself in many bankruptcies and a restructuring of the industry (Tveterås, 1999). This substantial cross-sectional difference in profitability can be explained by several factors or a combination of them, such as: output price, stochastic shocks, firm heterogeneity in terms of the quality of the farm location, and the quality of management.

Salmon prices are highly volatile and are potentially a major factor in explaining the variability in profitability. In 2003, the highest price per kilogram for a $4-5 \mathrm{~kg}$ salmon was $\left(\mathrm{NOK}^{1}\right.$ ) Norwegian kroner 22.49 (October)

Addess correspondence to Atle G. Guttormsen, Department of Economics and Resource Management, Norwegian University of Life Sciences, P.O Box 5003, N-1432 Aas, Norway. E-mail: atle.guttormsen@ umb.no 
and the lowest price was NOK 14.46 (July). Price fluctuations translate into significant price risk, since the magnitude and the direction of the week-toweek changes are often unknown to producers. Volatile prices make the timing of production extremely important. Selling 4-5 kg salmon in July for NOK 14.46 per kilogram will bring losses, whereas selling the same fish in October for NOK 22.49 per kilogram may be very profitable. The farmer has to frequently assess whether to harvest now to capture a known price, or to continue to feed to deliver a larger salmon at an unknown future price. Salmon is, to a large extent, sold on the spot market and no formalized derivative market exists; consequently, participants cannot hedge prices.

While prices are an obvious source of uncertainty, there are also several other factors that can have consequences of a similar magnitude. Biophysical conditions vary substantially over a year and between years and influence growth. For instance, in normal summers, growth is best in August and early September, but in warm summers seas become so hot that the fish stop feeding and hence growing. Stocking and harvesting decisions influence growth and capacity use rates and accordingly, profits. For instance, turnover can vary from a factor under one for good producers in good years to a factor close to two for a bad producer in a bad year. This difference in turnover can lead to almost double the production costs for the bad producer in a poor year.

The substantial variation in profits indicates that, if there were information that at least partly improves the producers' decisions, it will have value to the producers through the higher profits it creates. A way to measure the potential value of forecasting and decision support tools is to assess the value of the information they provide. The maximum value of any such model is that, if it provides certain information, this situation can then be used as a benchmark when assessing the maximum value of information.

In this article the primary discussion is about the value of information on price, and how such information can create value for the fish farmer. However, it should be noted that the same type of consideration can be carried out with respect to any factor that contributes to variability in profits. This topic will be addressed theoretically and exemplified by calculations of the value of price information for a full-scale fish farm.

\section{Value of Information}

The expected value of information is the expected increase in the value (or decrease in the loss) associated with obtaining more information about quantities relevant to the decision process. The expected value of information can be thought of as a measure of the importance of the uncertainty about a quantity in terms of the expected improvement in the decision that might be obtained from having additional information about it. Perfect information removes all uncertainty about the outcomes 
for the decision alternatives. While there is rarely an option in real-world business decisions that would actually remove all uncertainty, the value of perfect information provides an easily calculated benchmark about the worth of collecting additional information in building more reliable forecasts of future prices. If all the available options for collecting information cost more than the value of perfect information, then these options do not need to be analyzed in further detail. This is because imperfect information cannot be worth more than perfect information.

Value of information analysis is useful because it makes the losses associated with decision errors explicit, balances competing probabilities and costs, helps identify the decision alternative that minimizes the expected loss, prioritizes spending on research, and quantifies the value of the research to the decision maker. To illustrate the potential value of information in salmon farming, a relatively simple example will be provided. Assume that the fish-farmer has a pen with $n$ number of fish of size $4 \mathrm{~kg}$. The market price for a $4 \mathrm{~kg}$ salmon is NOK 25 per kilogram, and the value of the fish is hence NOK $n \times 4 \times 25$. The price next month is uncertain. The farmer must then decide if he or she will harvest the fish today, or wait a month or two. The model is now further simplified, and assumes that the fish farmer has only two choices: harvest today or harvest next month. It is also assumed that fish will not grow in the next month and that prices next month can take three different values. The price can stay at NOK 25, it can go up to NOK 30 or it can go down to NOK 20. The farmer initially believes that there is a $30 \%$ chance of an increase, a $30 \%$ chance of steady state, and a $40 \%$ chance of a decrease in prices. His decision problem can then be illustrated as in Figure 1.

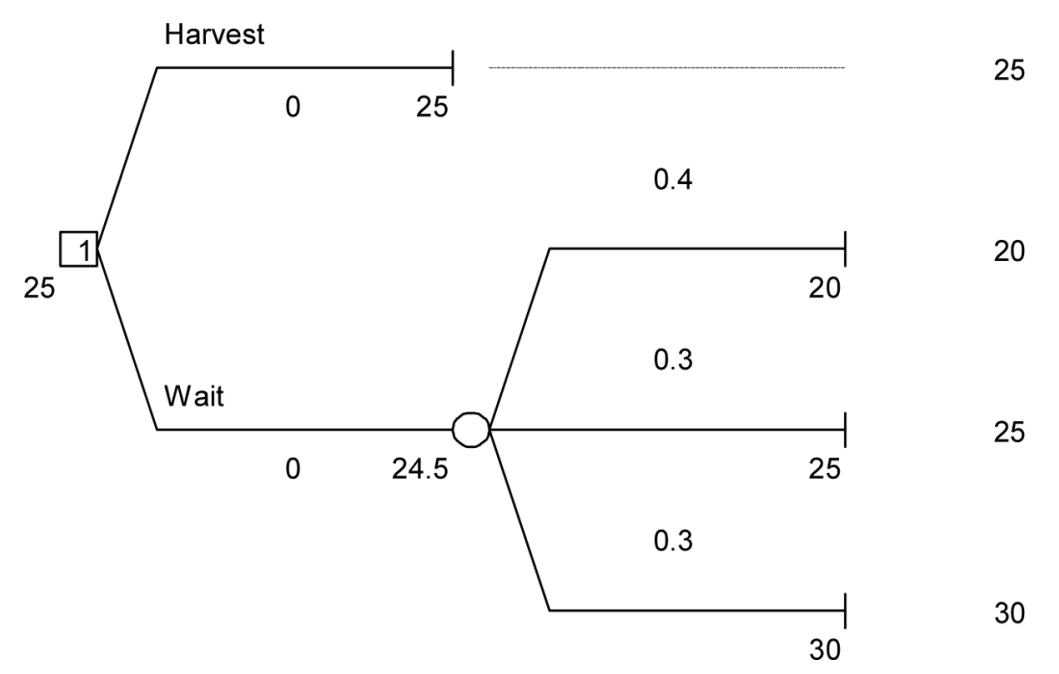

FIGURE 1 Decision tree for the fish harvesting example. 
The farmer can harvest and get NOK 25 per kilogram or wait one month and get NOK 20, 25 or 30 per kilogram with respective probabilities $0.4,0.3$, and 0.3. A risk-neutral farmer will maximize the net present value (NPV). For the harvest decision today, NPV is NOK 25 per kilogram, and for the wait and harvest next month decision NPV will be $(0.4 \times 20)+(0.3 \times 25)+$ $(0.3 \times 30)=24.5$. He or she will then decide to harvest today. Assume that someone with perfect insight offered to forecast the exact prices next month. The question is then how much is that information worth, i.e., how much would the farmer pay for that information? Instead of first taking action and then seeing the state of nature, this information can be built into a decision tree. However, since the outcomes are known before the decisions are made, some of the decisions can be ruled out. If the fish farmer knew that salmon prices would go down or stay constant, he would harvest immediately. If however he knew that prices would go up, the harvest would be postponed. Looking at Figure 2 the net present value will now be $(0.3 \times 30)+(0.7 \times 25)=26.5$. Although probabilities have not changed,

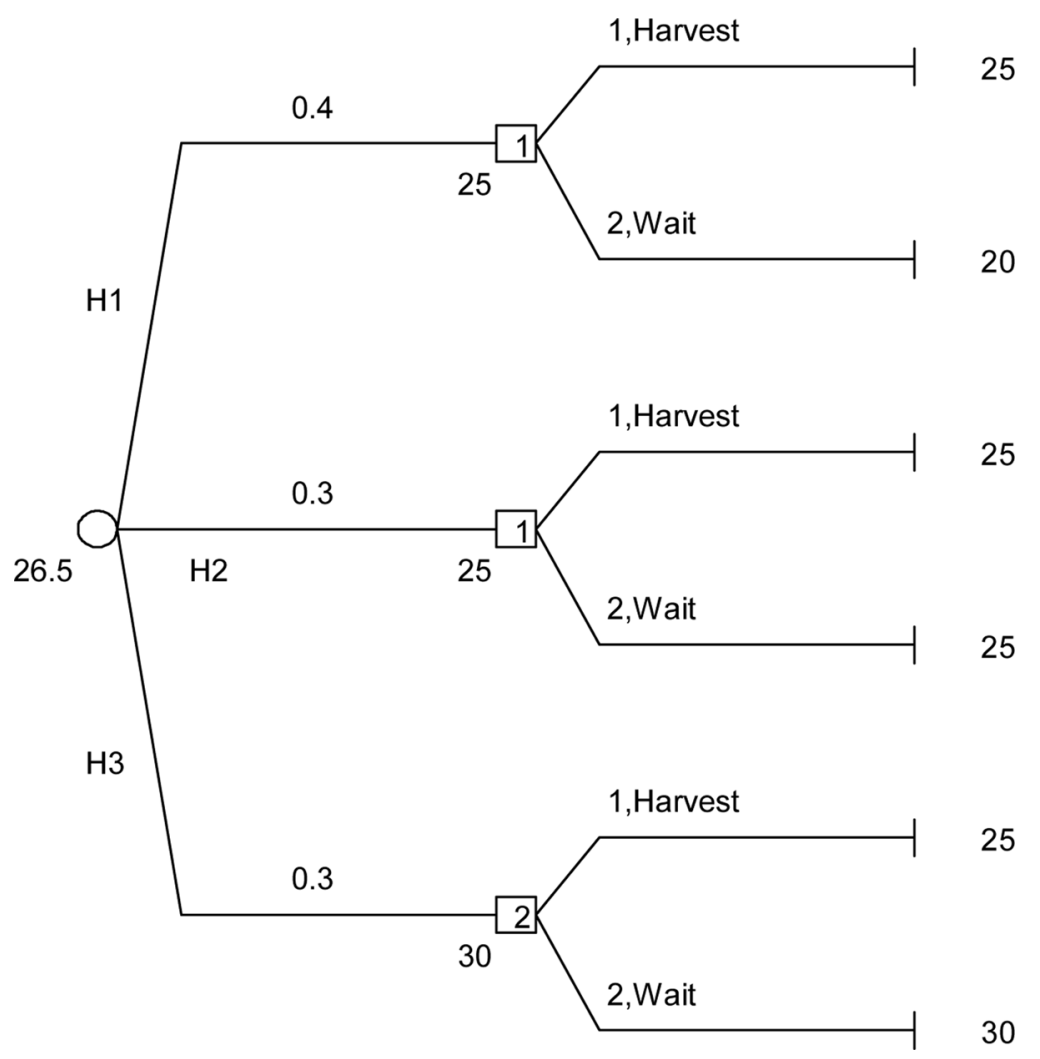

FIGURE 2 Value of perfect information. 
the expected value of the live fish has increased from 25 to 26.5 . The value of complete price information is therefore NOK 1.50 per kilogram of fish.

\section{Imperfect Information}

Perfect foresight about future salmon prices is only possible for farmers selling on contract. However, there are several papers indicating that it is possible to create forecasting models for fish prices that at least outperform naïve predictions, i.e., the price next month is the same as today. For instance, Guttormsen (1999) argued that relatively simple time series models could predict the direction of salmon price changes for 4, 8 and 12 weeks ahead with up to $80 \%$ accuracy. The following example will illustrate the value of imperfect information. The case illustration is further simplified by assuming that prices can only go up to NOK 30 or down to NOK 20. Based on the farmer's a priori beliefs, the probability for up is 0.4 and for down is 0.6. The present value is therefore NOK 24 for waiting and NOK 25 for harvesting today. A risk neutral farmer will then harvest now.

Let us suppose that someone offers to predict prices claiming that they can predict a price rise $80 \%$ of the time, and a price fall $70 \%$ of the time. How much should the farmer pay for that price information? Let us say that $\mathrm{H} 1$ is the price increase and $\mathrm{H} 2$ is the price decrease; " $\mathrm{H} 1$ " is the test signal (what the forecaster says) saying prices should increase and "H2" is the test signal saying prices should go down. Figure 3 illustrates this situation.

The simultaneous probability from the forecasting model is then the probability for a price increase. This tree can also be inverted, so that the

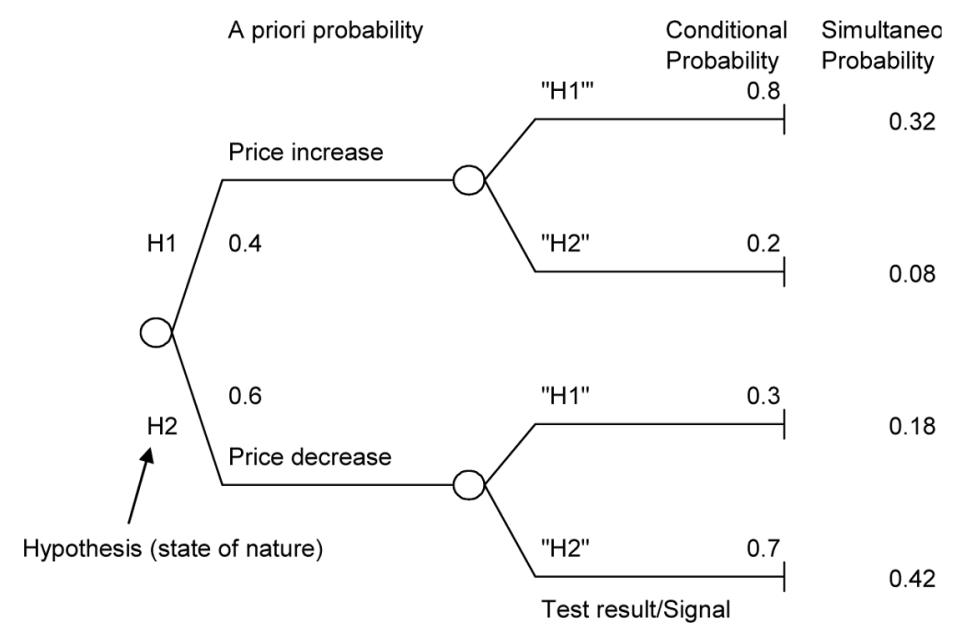

FIGURE 3 Decision tree for the fish harvesting example with sample information. 
TABLE 1 A Posteriori Probabilities

\begin{tabular}{lccc}
\hline State of nature & Prior & Posterior given prediction up & Posterior given prediction down \\
\hline Price up H1 & 0.4 & 0.64 & 0.16 \\
Price down H2 & 0.6 & 0.36 & 0.84 \\
\hline
\end{tabular}

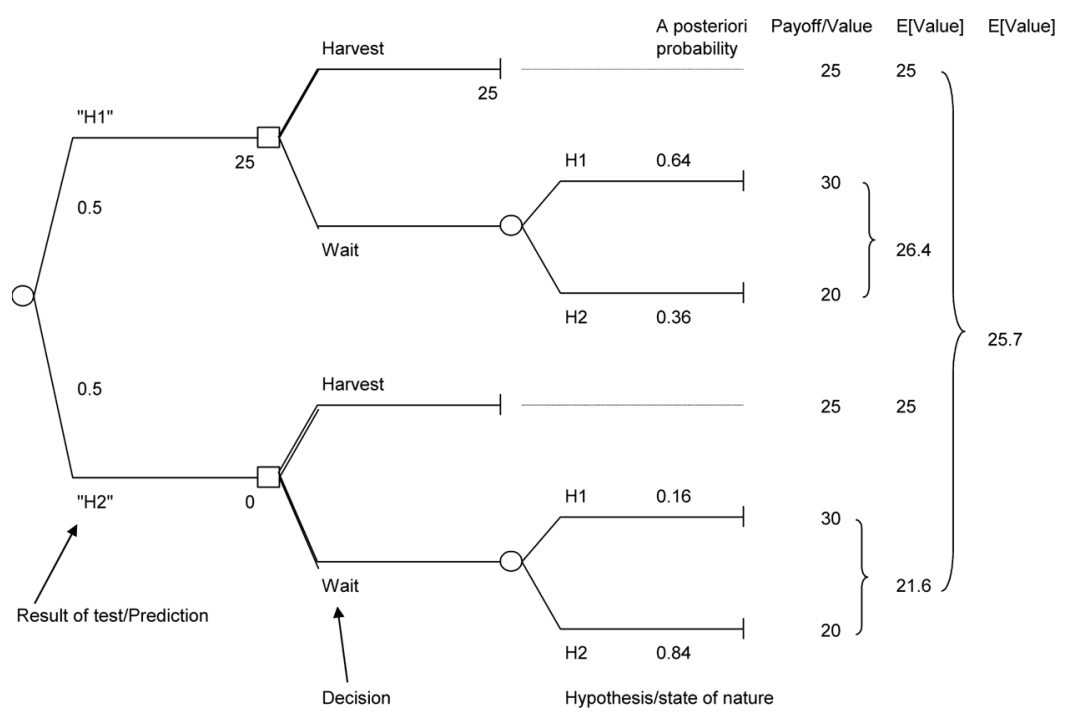

FIGURE 4 Inverted decision tree for the fish harvesting example with sample information.

signal (forecast) comes first. The probabilities for the signals can be estimated from the forecaster, and, by the use of Bayes theorem, get the a posteriori probabilities for price increase and price decrease. The a posteriori probabilities are presented in Table 1.

The fish farmer should harvest now if the price forecaster says that prices will go down, and wait if the price forecaster says that prices will go up. Based on these new probabilities, the NPV of the harvesting decision can be recalculated (Figure 4 ).

The expected value of imperfect information in this situation is hence NOK 0.70 per kilogram.

\section{Salmon Price Information}

The example above illustrates that information about future salmon prices has the potential to create value for the fish farmer. In this section, the discussion will be focused on the question of whether it is possible to obtain price information just by examining historical prices. There is a relatively large number of studies analyzing supply and demand and market 
structure for salmon (Asche, Bjørndal, \& Salvanes, 1998; Asche, Bremnes, \& Wessels, 1999; Asche et al., 2005). These studies offer valuable insights into markets and how consumers behave, but such models may have limited value for the producers' short-term decisions. This article focuses on the possibilities of finding price characteristics that can be identified without using an advanced time series technique.

Salmon prices are determined, like other prices, by the law of supply and demand. Hence, the correct salmon price is the price consumers are willing to pay for the quantity (and quality) supplied. Furthermore, over time, a company will produce up to the point where the cost of producing the last unit equals the price it is being offered in the market. This is intuitive since prices higher than operating costs will attract new entrants and stimulate existing producers to increase their production. With prices lower than cost, the situation will be reversed: high-cost producers will exit the industry and those still producing will attempt to lower their production. This rule holds for competitive industries, and history indicates that it also holds for salmon farming. Figure 5 presents real market prices together with operating costs, and one can see that the price-cost margin has been fairly stable. Costs of production have decreased substantially, and this again has led to lower prices.

In contrast to the relatively stable long-term price pattern, salmon prices exhibit large week-to-week fluctuations. In addition, prices for salmon of different weight classes do not move synchronously. Week-toweek fluctuations are of more interest for management decisions in general and for the harvesting decision especially. Therefore, in this section, the

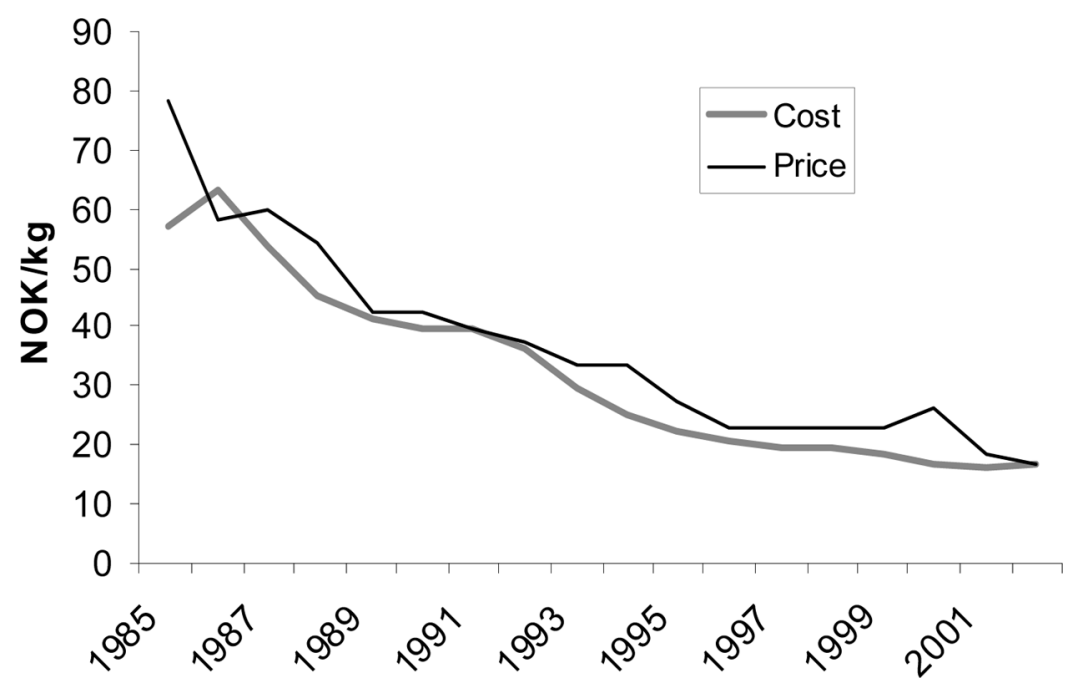

FIGURE 5 Operating cost versus prices for Norwegian salmon. 


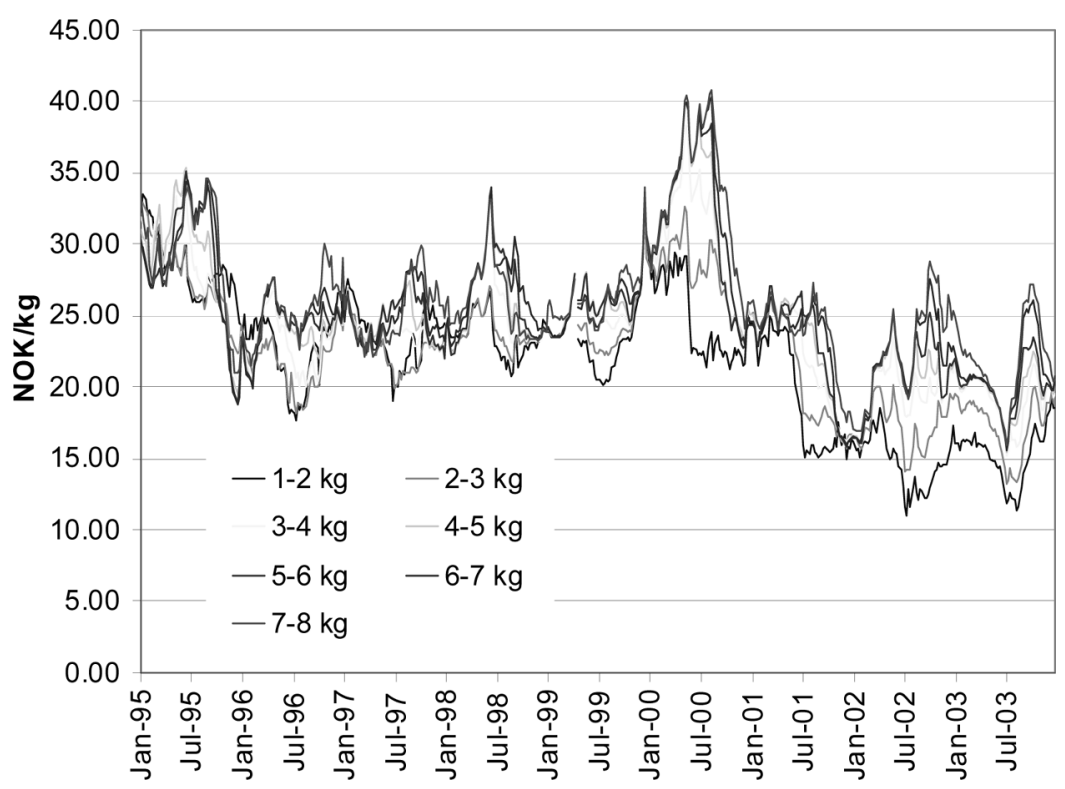

FIGURE 6 Weekly salmon prices 1995-2003 for different weight classes.

discussion will be centered on some factors that might affect demand and supply in the short term, and hence influence short-term price determination. The discussion will be divided in two parts, one part focusing on absolute prices, and one part focusing on relative price relationships.

The strong week-to-week fluctuations are illustrated in Figure 6. So while the long-term trend, relatively speaking, showed a rather stable pattern, the short-term prices are fluctuating severely.

\section{Absolute Prices}

Deterministic factors are reoccurring cycles or phenomena that, independently of other market conditions alter supply or demand. In this section, regular events will be examined and especially study whether any of the substantial within-year fluctuations can be explained by deterministic calendar-dependent events such as Christmas, Easter, summer or winter. Seasonal patterns in salmon prices will also be investigated. This is interesting since such factors might explain price increases/decreases that are difficult to explain in other ways. For instance, from time to time people involved in the business claim that prices go up around Christmas. There are numerous reasons for salmon prices to vary between seasons. The main reason is that salmon production is biological, i.e., strongly dependent upon weather and climatic conditions. Hence, cost of production will vary dependent upon when the fish is required for harvesting, i.e., the cost of producing a 


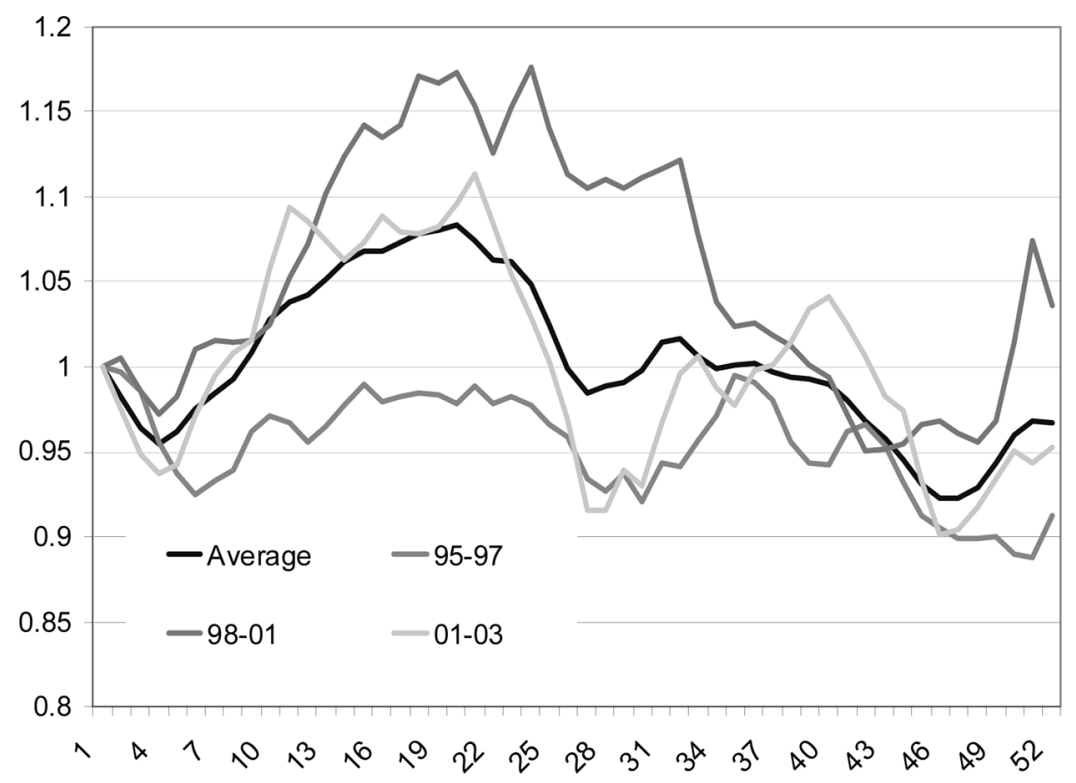

FIGURE 7 Normalized prices week by week, by periods of 3 aggregated years.

salmon ready for marketing in May might differ from the cost of producing a similar fish ready for marketing in October. Also, calendar-dependent changes in demand can influence prices. However, if these changes in demand are expected, farmers might adjust their production to them.

Several statistical tools exist for revealing seasonality in prices. A relatively simple and illustrative way is to draw the yearly plot of normalized prices. Prices can be normalized to the price in week 1 . That is, if prices in week 12 are higher than in week 1, the normalized price will be higher than 1, and if prices in week 12 are lower than prices in week 1 , the normalized price will be less than 1. Such a graph is presented in Figure 7 with normalized prices for the years from 1995 to 2003 . However, to make the picture more clear, average prices over a 3-year period are presented.

Figure 7 shows that there are relatively distinct seasonal patterns. For most years, prices peak some time between week 20 and 24, i.e., salmon price seems to reach its yearly high some time between May 15 and June 15. Prices then decrease to around week 27, increasing again before lowest prices are reached sometime between week 45 and week 50, i.e., sometime during November. Figure 7 show that prices in the "high price" period are on average $20 \%$ higher than in the "low price" period. Based on the graph, boosted Christmas prices are not a general rule. However, since increased demand before Christmas is an indisputable fact, it seems that farmers have adjusted to the increased demand, with a complementary increase in supply. 


\section{Relative Prices}

Until now, salmon has been viewed as an aggregate product: Atlantic salmon. The large variations in prices for different types or sizes of salmon have not yet been studied. Such aggregation works well when discussing fundamental trends, but disaggregating might reveal even more information about the underlying factors important for harvesting decisions. Now, the relationship between prices for fish of different sizes will be examined. Figure 6 illustrates the importance of disaggregating prices. There are relatively large variations in prices for the different sizes. While the large fish tend to fetch a somewhat higher price than small fish, this result is not clear-cut. There also seems to be even stronger seasonality in the disaggregated data compared to the aggregated data.

Asche and Guttormsen (2001) argue that there exists a stable pattern in the relationship between prices for different sizes of salmon. Based on the model presented in Bjørndal (1988) they further argue that this price relationship should have consequences for harvesting models. Figure 8 is an updated version of a similar figure to one presented in Asche and Guttormsen (2001). The relative prices have been constructed by dividing the prices for $1-3 \mathrm{~kg}$, and $5-7 \mathrm{~kg}$ fish by the benchmark size $3-5 \mathrm{~kg}$. The pattern first recognized by Asche and Guttormsen (2001) still exists. However, the relationship between different sizes has changed slightly. Cycles lasting for approximately 1 year can be observed. Salmon in the higher weight

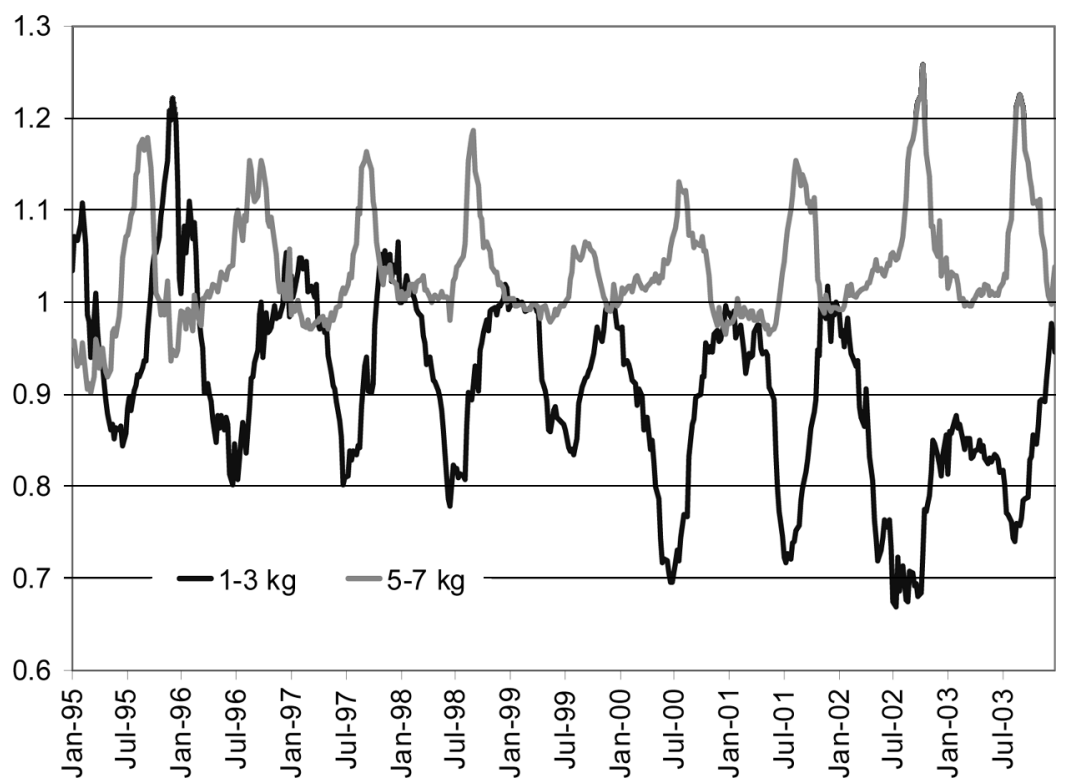

FIGURE 8 Prices of $1-3 \mathrm{~kg}$ and $5-7 \mathrm{~kg}$ Norwegian salmon relative to $3-5 \mathrm{~kg}$ salmon. 
classes are relatively more expensive during August and September. In these months, $5-7 \mathrm{~kg}$ salmon are sold for about $115 \%$ of the unit price for 3-5 kg fish. In February and March the unit price of large salmon is slightly lower than that for $3-5 \mathrm{~kg}$ salmon. The pattern for the smaller salmon is different. The smallest weight classes are relatively most expensive in November and December, and relatively cheapest in July. For an explanation of this pattern, see Asche and Guttormsen (2001).

\section{Optimal Harvesting Model}

In this section, it will be shown that the optimal harvesting time is closely related to price variations. Generally, one should not harvest when the marginal revenue from waiting is greater than the marginal cost. Bjørndal (1988) establishes the link to the classical forestry problem and uses analytical optimization theory to study the optimal harvest time under different cost assumptions. Bjørndal based his model on a constant relationship between the unit price and fish size. In particular, he assumed that unit price was a positive linear function of the weight of the individual fish. Mistiaen and Strand (1998) recognized that the relationship between individual fish weight and unit prices may not be continuous, but rather, subject to discrete jumps at given threshold sizes, i.e., the price function is piecewise continuous. However, Mistiaen and Strand (1998) and Bjørndal (1988) based their definition of the price processes on observations from one single market day, but failed to observe the dynamics in relative prices. Hence, all these studies assume that the relationship between the prices (per kilogram) of different sizes of fish is stable, i.e., that relative prices are constant over time.

The relationship between unit prices for different sized Norwegian salmon varies over time with yearly cycles. At some times of the year small fish have a higher unit price than large fish, while the relationship is opposite at other times of the year. This seasonality will most likely impact the determination of the marginal value of delaying harvest and consequently the optimal harvest time. This is because when the relative prices are not constant over time, the marginal value of delaying harvest is dependent upon future prices and future weight of the fish. This implies that the optimal harvest decision for, say, a $2.5 \mathrm{~kg}$ fish might be to harvest now if the month is January, while it might be optimal to wait if the decision is taken is June.

To better illustrate the importance of knowledge of relative price relationships, a simplified and shortened version of the model provided in Bjørndal (1988) will be presented. The model concerns one cohort of fish, a one-time investment, and starts with the value of a year class of fish. This value, $V(t)$, is found by multiplying price times quantity, defined by 


$$
V(t)=p(w) B(t)=p(w) R e^{-M t} w(t)
$$

where $p(w)$ is the price per kilogram of fish of weight $w, B(t)$ is the biomass, $R$ is number of recruits released, and $M$ is natural mortality. $M$ can be treated as constant or may vary through time with respect to fish size and/or time of the year. Assuming zero cost, the fish farmer will harvest at the time that maximizes the present biomass value as considered at the time of releasing the fish.

$$
\underset{\{0 \leq t \leq T\}}{\operatorname{Max}} \pi(t)=V(t) e^{-r t}
$$

The first-order condition is

$$
\pi^{\prime}(t)=V^{\prime}(t) e^{-r t}-r V(t) e^{-r t}=0
$$

and the optimal harvesting time thus satisfies

$$
V^{\prime}\left(t^{*}\right)=r V\left(t^{*}\right)
$$

By finding the changes in $V(t)$ over time and evaluating the separate elements in the biomass value more closely, a better understanding of the harvesting rule is acquired. This rule says that the fish must be harvested when the marginal increase in the value of the "natural capital," i.e., fish in the sea, equals the opportunity cost:

$$
V^{\prime}\left(t^{*}\right)=\left\{\frac{p^{\prime}(w)}{p(w)} w^{\prime}\left(t^{*}\right)-M+\frac{w^{\prime}\left(t^{*}\right)}{w\left(t^{*}\right)}\right\} V\left(t^{*}\right)=r V\left(t^{*}\right)
$$

The above expression can be rewritten as

$$
\frac{p^{\prime}(w)}{p(w)} w^{\prime}\left(t^{*}\right)+\frac{w^{\prime}\left(t^{*}\right)}{w\left(t^{*}\right)}=r+M
$$

Equation (6) illustrates the importance of relative prices, here in the form of change in prices as a function of changes in weight $p^{\prime}(w)$. The results presented above indicate that the sign of $p^{\prime}(w)$ varies through the year, making $p^{\prime}(w)$ dependent on time, i.e., $p^{\prime}(w, t)$. This changes the optimization problem, and might have important implications for calculating optimal harvesting time. However, the fact that the relative price changes between different salmon sizes over the year makes the mathematics less tractable. If one is to take the pattern in relative prices between sizes into account, it will be impossible to find analytical solutions, and numerical methods must be applied. 
The above model is rather theoretical, but is included to illustrate how closely linked the optimal harvesting decisions are to the development of prices. The model also illustrates that optimal harvesting time is determined by the price level and the relative prices between different sizes of fish. The optimal harvesting time calculated in the model will never be applied to practical situations unless the farmer has perfect foresight of future price levels and future relative price relationships.

Theoretical models, like the model presented her, provide important qualitative insight into harvesting times. However, they have severe shortcomings when it comes to practical implementation in full-scale fish farming. The models do not include several important features of fish farming, such as the capacity limit of the farm, seasonal fluctuations in market prices, multi-cohort management or the optimal harvesting of the various size-classes.

Pascoe, Wattage, and Naik (2002) examined actual harvesting strategies employed by commercial aquaculture producers with theoretically optimal strategies derived from standard bioeconomic models. Their main result is that actual harvesting strategies differ significantly from the theoretical models. They discuss several possible reasons for that, but conclude that "it is more likely that the models are not sufficient in identifying the appropriate strategy given the risks and uncertainties faced," and further, "different modeling approaches may be more appropriate, such as the dynamic programming approaches..."

The production planning model presented in Forsberg (1999) is a practical production planning model that has the ability to take all the restrictions into consideration. This model will therefore be used to illustrate the possible value of price information. To illustrate the importance of price information, the harvesting plans are optimized based on different price scenarios. Profit is then evaluated ex post.

\section{The Forsberg (1999) Harvesting Model}

The model is carefully described in Forsberg (1999) so only some key features will be described here. Forsberg (1999) presents two types of harvesting management strategies: batch harvesting $(\mathrm{BH})$ and graded harvesting $(\mathrm{GH})$. Only batch harvesting will be considered here. BH strategy operates by: (1) stocking an individual fish group into the grow-out system at given times; (2) feeding the individual fish group in isolation from other cohorts; and (3) harvesting the entire individual fish group or a part of the cohort, as their mean size reaches market size. Various approaches to BH strategies are described in Lewis and Benham (1973), Hilge (1979), Paessum and Allison (1984), Watten (1992), Forsberg et al. (1993), and Summerfelt et al. (1993). 
$\mathrm{BH}$ is operated by crowding the standing stock in the production cage and hauling a batch containing the preferred number of harvested fish. These are then transferred into separate cages (starving cages). Harvested fish placed in the starving cages are starved for about 10-14 days before being transferred to well-boats and shipped alive to the processing plants and slaughtered. The harvested fish are, by this method, randomly sampled from the standing stock, which implies that mean size and standard deviation of harvested fish is assumed to be equal to those of the standing stock. This is the most common harvesting method in salmon farms.

\section{The Model Farm}

Important assumptions are listed in Table 2. The planning period starts January 1, with three fish groups weighing 2.0, 2.5, and $3.0 \mathrm{~kg}$, respectively. Each group contains 25, 000 fish, and starting biomass is hence 187.5 metric tons. To make the situation as comparable as possible with the real situation in Norway, feed supply is restricted to 250 metric tons per year for the three groups, as total feed used on each farm is regulated by a government set quota. ${ }^{2}$ The objective is to maximize NPV.

Based on the above presentations of salmon prices, optimal harvesting plans are calculated on the basis of the following price scenarios:

Scenario 1: Constant price per kilogram regardless of fish size.

Scenario 2: Seasonal adjusted prices, same price regardless of fish size.

Scenario 3: Seasonal adjusted prices, dynamic weight dependent.

Scenario 4: Actual prices.

Scenario 1 is hence the no-information scenario while scenario 4 is the perfect information scenario. Scenarios 2 and 3 include different amounts of historical information about price behavior. The value of historical price

TABLE 2 Assumptions, Model Farm

- Three fish groups: 2.0, 2.5 and $3.0 \mathrm{~kg}$ at January 1

- Fish number: 25000 for each fish group

- IB biomass: 187.5 metric tons

- Growth and mortality normal for southwest Norway

- Restricted feed supply (250 mt/yr for the three groups)

- Feed costs increase with increasing fish size; ranging from NOK 8.00 per $\mathrm{kg}$ fish at $2 \mathrm{~kg}$ to NOK 9.50 per $\mathrm{kg}$ at $7 \mathrm{~kg}$

- Slaughtering cost (NOK 3.50 per $\mathrm{kg}$ harvested)

- Objective: Maximize net present value $(r=1 \%$ per month) 
information is the extra profit that is gained by including that information in harvesting decisions. An upper boundary for the value of price information is the profit from scenario 4 minus the profit from scenario 1 . Scenarios 1 to 3 are based on real historical prices, from the 2001-2002 periods, and actual prices are based on prices from 2003.

\section{Harvesting Plans and Value of Information}

Harvesting plans, profit, and the value of information are presented in Table 3. The first impression is that the plans do not change very much between the different scenarios. For three out of four scenarios all the fish are harvested during September and October. The only large outlier is scenario 2 where all fish are harvested in May. This is an interesting result since the only difference between scenarios 2 and 3 , is that in scenario 3 where the relative price relationship between different-sized fish varied throughout the year. Prices on $3-5 \mathrm{~kg}$ fish are the same in both scenarios. These results emphasize the point made by Asche and Guttormsen (2001) that the pattern in relative price relationships has important implications for the calculation of optimal harvesting times.

To calculate the value of information, profits from operation in the planning period, January 1 to harvest, are calculated. Only two variable costs are considered: feed and harvesting cost. These simplifications will slightly

TABLE 3 Harvesting Plan, Profit and Value of Information (VOI) for Different Price Scenarios and Fish Groups

\begin{tabular}{|c|c|c|c|c|c|}
\hline & May & Sept & October & Profit in $1000^{a}$ & $\mathrm{VOI}^{b}$ \\
\hline \multicolumn{6}{|l|}{ Scenario 1} \\
\hline Group 1 & & & $103(5.3 \mathrm{~kg})$ & & \\
\hline Group 2 & & & $122(6.3 \mathrm{~kg})$ & 279 & 0 \\
\hline Group 3 & & $68(6.4 \mathrm{~kg})$ & $64(7.2 \mathrm{~kg})$ & & \\
\hline \multicolumn{6}{|l|}{ Scenario 2} \\
\hline Group 1 & $54(2.6 \mathrm{~kg})$ & & & & \\
\hline Group 2 & $66(3.2 \mathrm{~kg})$ & & & 444 & 165 \\
\hline Group 3 & $78(3.8 \mathrm{~kg})$ & & & & \\
\hline \multicolumn{6}{|l|}{ Scenario 3} \\
\hline Group 1 & & $62(4.7 \mathrm{~kg})$ & $34(5.3 \mathrm{~kg})$ & & \\
\hline Group 2 & & & $122(6.3 \mathrm{~kg})$ & 592 & 313 \\
\hline Group 3 & & & $139(7.2 \mathrm{~kg})$ & & \\
\hline \multicolumn{6}{|l|}{ Scenario 4} \\
\hline Group 1 & & $92(4.7 \mathrm{~kg})$ & & & \\
\hline Group 2 & & $109(5.6 \mathrm{~kg})$ & & 1279 & 1000 \\
\hline Group 3 & & $125(6.4 \mathrm{~kg})$ & & & \\
\hline
\end{tabular}

Average weight of the harvested fish in parentheses.

${ }^{a}$ Profits from operation in the planning period, i.e., (Sales income - Variable cost) - Value of the fish by January 1.

${ }^{b}$ VOI is extra profit compared to scenario 1. 
overestimate the profits, but should not alter the conclusion about information value. Based on the results from the model, there is no doubt that perfect information has a relatively high value. A farmer, who could exactly predict the prices for all weight classes in all months of the next year, would nearly triple his or her profit, compared to the uninformed farmer.

However, perfect foresight is not possible, so it is probably more interesting to look at the value of sample information, i.e., scenarios 2 and 3. Both plans where some information about future prices are known outperform the no-information scenario. The value of information is NOK 165,000 and 313,000 , respectively.

\section{CONCLUDING REMARKS}

The substantial variability in the profitability of salmon farms indicates that information that improves decision-making has substantial value. A good decision support model provides information that allows the farmer to time production and harvesting decisions well in relation to the factors that primarily contribute to price volatility. Prices are among the most volatile factors in the farmers' decision process, and are really the only factors that contribute to the variability in profits that have received any attention in the academic literature. Bringing the information from forecasting models into the harvesting decision pulls together the two main research topics regarding management practice in fish farming: production planning and forecasting of prices.

Volatile salmon prices make the timing of harvesting an important factor for profitability in salmon farming. The fish farmer has to decide whether to harvest and market the fish at a known price, or to continue to feed until a later harvest and market a larger salmon at an unknown future price. When prices vary between NOK 14 and NOK 22 for different sizes at different times, harvesting the right fish at the right time is potentially a key factor for success in the fish farming industry.

The theoretical examples and the results from a simplified full-scale model farm, emphasize that price information has the potential to create extra profit for the farmer. In our salmon farm example based on the model presented in Forsberg (1999), fully informed farmers more than tripled their profits compared to farmers basing their decisions on a fairly naïve decision model. Also, the farmers who utilized only historical price information improved their results substantially, indicating that sample information creates value. However, it is important to bear in mind that our examples are based on one year, and that the choice of another time period for the construction of price scenarios could alter the results.

The harvesting model used in this article is more complex than most of the theoretical models presented in the literature. However, the example is 
still simplified, and the results should be taken as indicative of the value of information. In practice, fish farmers do add several other restrictions into their harvesting decision-making in order to ensure the operations are practically feasible, such as: (1) using the full capacity of a well-boat when the farmer decides to harvest; (2) balancing harvested biomass with the operational workload, transportation, and processing capacity; (3) harvesting fish over a limited size range in order to meet market demand; and (4) reducing the number of harvest operations in order to avoid such negatives as stress in fish (Forsberg, 1999). Including more restrictions in the harvesting model would probably increase the cost of providing the higher valued fish, and hence reduce the value of price information.

New innovations that allow fish farmers to size-grade the most profitable size class from the livestock prior to harvesting (GH strategy), will undoubtedly give fish farmers a better tool to exploit the variation in relative prices more optimally, and to better take account of price peaks. Forsberg (1999) has demonstrated that GH strategies can be as high as $10 \%$ more profitable than batch harvesting strategies where both small and large fish in a stock will be harvested simultaneously. The differences between $\mathrm{GH}$ and $\mathrm{BH}$ strategies are, however, a subject for further studies.

\section{NOTES}

1. $\mathrm{NOK}=100=\mathrm{EUR} 11.95=\mathrm{USD}$ 14.65. September 22, 2004 (www.oanda.com).

2. See Kinnucan and Myrland (2002) for a discussion of these regulations.

\section{REFERENCES}

Asche, F., Bjørndal, T. \& Salvanes, K.G. (1998) The demand for salmon in the European Union: the importance of product form and origin. Canadian Journal of Agricultural Economics, 46(1), 69-81.

Asche, F., Bremnes, H. \& Wessells, C.R. (1999) Product aggregation, market integration and relationships between prices: an application to world salmon markets. American Journal of Agriculture Economics, 81, 568-581.

Asche, F. \& Guttormsen, A.G. (2001) Patterns in relative price for different sizes of farmed fish. Marine Resource Economics, 16, 235-247.

Asche, F., Guttormsen, A.G., Sebulonsen, T. \& Sissener, E.H. (2005) Competition between farmed and wild salmon: the Japanese salmon market. Agricultural Economics, 33(3), 333-340.

Bjørndal, T. (1988) Optimal harvesting of farmed fish. Marine Resource Economics, 5, 139-159.

Forsberg, O.I. (1999) Optimal harvesting of farmed Atlantic salmon at two cohort management strategies and different harvest operation restrictions. Aquaculture Economics and Management, 3(2), 143-158.

Forsberg, O.I., Sanni, S. \& Bergheim, A. (1993) Operation model for optimised landbased farming of Atlantic salmon. In: Fish Farming Technology (eds H. Reinertsen, L.A. Dahle, L. Jørgensen \& K. Tvinnereim), pp 401-407. A. A. Balkema, Rotterdam.

Guttormsen, A.G. (1999) Forecasting weekly salmon prices: risk management in salmon farming. Aquaculture Economics and Management, 3, 159-166.

Hilge, V. (1979) Biological and economical aspects of fish production in closed warm-water system. In: Advance in Aquaculture (eds V.R. Pillay \& W.A. Dill), pp 505-508. Fishing News (Books) Ltd, Surrey, UK. 
Kinnucan, H. \& Myrland, Ø. (2002) The relative impact of the Norway-EU Salmon Agreement: A midterm assessment. Journal of Agricultural Economics, 53, 195-219.

Lewis, E.R. \& Benham, K. (1973) Year-around trout production through temperature control. American Fishes and US Trout News, 18, 6-13.

Mistiaen, J.A. \& Strand, I. (1998) Optimal feeding and harvest time for fish with weight-dependent prices. Marine Resource Economics, 13, 231-246.

Paessum, M. \& Allison, R. (1984) Maximising tilapia production in recirculating systems by sequential rearing. Aquaculture, 42, 185-189.

Pascoe, S., Wattage, P. \& Naik, D. (2002) Optimal harvesting strategies: practice versus theory. Aquaculture Economics and Management, 6(5-6), 295-308.

Summerfelt, S.T., Hankins, J.A., Summerfelt, S.R. \& Heinen, J.M. (1993) Modeling continuous culture with periodic stocking and selective harvesting to measure the effect on productivity and biomass capacity to fish culture systems, In: Techniques for Modern Aquaculture (ed J.K. Wang), pp 581-595. Proceedings of the Aquatic Engineering Conference, Spokane, Washington. ASAE Publication 02-93. American Society of Agricultural Engineers, MI, USA.

Tveterås, R. (1999) Production risk and productivity growth: some findings for Norwegian salmon aquaculture. Journal of Productivity Analysis, 12, 161-179.

Watten, B. (1992) Modelling the effects of sequential rearing on the potential production of controlled environment fish-culture systems. Aquacultural Engineering, 11, 33-46. 